Historia y comunicación social

ISSN-e 1988-3056

https://dx.doi.org/10.5209/hics.66311

\title{
Modesto Sánchez Ortiz, comunicador y tratadista del Periodismo
}

\author{
Manuel Jesús Cartes Barroso ${ }^{1}$
}

Recibido: 12 de octubre de 2017. / Aceptado: 30 de septiembre de 2018.

Resumen. El presente artículo tiene como objetivo abordar el prácticamente desconocido perfil biográfico de Modesto Sánchez Ortiz (Aljaraque, 1857-Madrid, 1937), un periodista onubense "hecho a sí mismo" en las últimas décadas del siglo XIX y comienzos de la siguiente centuria. Figura muy vinculada a la Política, de su recorrido periodístico cabe destacar, entre otros logros, la sabia dirección y modernización del diario La Vanguardia, así como la redacción del libro El Periodismo, un manual sobre la profesión periodística que le convierte en uno de los primeros tratadistas sobre el Periodismo en España. A pesar de ello es poco recordado en la actualidad, por lo que pretendemos rescatar, con nuevos datos inéditos, la trayectoria de quien iniciase una importante saga de periodistas y escritores que continúa en los días actuales.

Palabras clave: Periodismo; tratadista; La Vanguardia; Política; España

\section{[en] Modesto Sánchez Ortiz, communicator and treatise writer on Journalism}

Abstract. This paper aims to approach the almost unknown biographical profile of Modesto Sánchez Ortiz (Aljaraque, 1857-Madrid, 1937), an Onubense self-made journalist in the last decades of the 19th century and the beginning of the 20th century. Very linked to Politics, from his journalistic career we can highlight, among other achievements, the intelligent management and the modernization of the newspaper La Vanguardia, as well as the writing of El Periodismo, a book about the journalistic profession that makes him one of the first treatise writers on Journalism in Spain. Despite this, he is little remembered today, so we intend to recover the trajectory of a person who started an important dynasty of journalists and writers that continues today, with new unpublished data.

Keywords: Journalism; treatise writer; La Vanguardia; Politics; Spain

Sumario: 1. Introducción. 2. Perfil y recorrido periodístico: nuevos datos para una biografía incompleta. 3. Actividad política y red de contactos. 4. Teórico del Periodismo español. 4.1. El Periodismo como sacerdocio y magisterio. 4.2. Estado del Periodismo español. 4.3. Periodismo de empresa frente al periodismo de partido. 4.4. Algunos pecados periodísticos. 4.5. Asociacionismo periodístico. 5. Conclusiones. 6. Referencias.

Cómo citar: Cartes Barroso, M. J. (2019). Modesto Sánchez Ortiz, comunicador y tratadista del Periodismo, en Historia y comunicación social 24 (2), 727-742.

\footnotetext{
Universidad de Sevilla.

cartesbarroso@us.es
} 


\section{Introducción}

Tienen los municipios y sus gentes, con especial frecuencia en España, la falta de olvidar la figura de sus hijos más célebres, muchos de los cuales llevaron el nombre de sus pueblos o ciudades de nacimiento más allá que en sus documentos o cédulas de identidad. Así se ha silenciado en multitud de ocasiones la voz y el nombre de aquellos que, dentro o fuera de sus poblaciones, consiguieron éxitos o hazañas personales sin olvidar nunca su cuna natalicia. Y otras veces, del reconocimiento otorgado se pasó al olvido casi absoluto, a la postergación. En cierto sentido, este último caso ha sido el de Modesto Sánchez Ortiz (1857-1937), un personaje que al amparo de la Política forjó y proyectó una imagen pública muy reconocida en su tiempo, si bien casi olvidada en la actualidad, como exploramos al comienzo de esta investigación.

Periodista, redactor, articulista y político onubense de nacimiento, Sánchez Ortiz fue conocido por dirigir importantes publicaciones como La Vanguardia, a la que transformó radicalmente con un aspecto europeo. Su carrera periodística la desarroló en Madrid y Barcelona, las dos principales ciudades de España. Por otro lado, es considerado como uno de los primeros teorizantes del Periodismo en España, a comienzos del siglo XX, cuando aún no existían facultades de Ciencias de la Información o Comunicación y eran escasos los estudios sobre esta disciplina en nuestro país.

Estos son, sin duda, los dos logros más relevantes de Sánchez Ortiz, que han sido ya abordados en algunos trabajos y publicaciones de carácter científico, por autores como Voltes Bou (1979), Casasús Guri (1989; 1990), García Galindo (2005) o Sanmartí Roset (2016). Sin embargo, el periodista onubense fue algo más que el director de La Vanguardia y el autor de El Periodismo, al ser una de las personalidades del mundo de la Comunicación y de la Política más reconocidas en la España de la Restauración borbónica, toda vez que trabajó para el Gobierno y colaboró en diversos diarios y periódicos hasta prácticamente el final de sus días. Y, además, fue el precursor de una familia de periodistas, comunicadores y escritores: los Sánchez.

Por todo ello, el objetivo de la presente investigación es realizar un breve estudio de la vida y obra de Sánchez Ortiz. En los próximos apartados se analiza su figura y su trayectoria periodística y política y, además, se resalta igualmente su rol de tratadista del Periodismo español. En primer lugar, este trabajo se basa en la desigual bibliografía existente sobre el autor y, posteriormente, en las pesquisas que hemos desarrollado sobre la prensa histórica existente en la hemeroteca histórica del Ayuntamiento de Huelva, el archivo de la Diputación de Huelva y la hemeroteca digital de la Biblioteca Nacional de España. En este sentido, han sido especialmente interesantes los testimonios hallados que el autor publica en diversos periódicos, a modo de memorias, en sus últimos años de vida. Al mismo tiempo, realizamos un análisis descriptivo de su reconocida obra El Periodismo, de la que conservamos primorosamente una primera edición en nuestra biblioteca particular. En conclusión, con estas líneas pretendemos rescatar del olvido la figura de un personaje clave en la historia del Periodismo de la España de finales del siglo XIX y comienzos del XX. 


\section{Perfil y recorrido periodístico: nuevos datos para una biografía incompleta}

Modesto Clímaco Rafael Cayetano Sánchez Ortiz nació el 30 de marzo de 1857 en Aljaraque, en la provincia de Huelva. Criado en el seno de una familia de ricos labradores, fue hijo de Simón Sánchez Díaz, natural de La Redondela (Huelva), y de Tomasa Ortiz González, de Aljaraque ${ }^{2}$. Su infancia transcurre en el municipio de origen, próximo a Huelva, una ciudad que dos décadas antes había sido elegida capital de la provincia onubense. Ya en su juventud se traslada a vivir a Madrid, donde primeramente desarrollará diversos trabajos, como por ejemplo practicante en un hospital o mancebo de farmacia. Esas ocupaciones, junto al placer de la lectura, las compagina con estudios de Derecho y Medicina, lejanos a la profesión periodística que inmediatamente harían que su nombre comenzara a ser conocido (Carmona y Caballero, 2010a).

Puede decirse que su carrera periodística se inicia en 1876, con casi veinte años. Por aquel entonces era secretario de Eulogio Florentino Sanz. Merced a la intercesión de este escritor intenta publicar un artículo en el diario El Imparcial, titulado 'Mi primer artículo' (Sánchez Ortiz, 24 de enero de 1933), aunque desconocemos si lo consiguió finalmente. Por otro lado, sabemos que en 1881 trabaja como redactor en el periódico El Nacional y, posteriormente, en el madrileño diario El Correo, en el periodo de 1881 a 1888 (Sánchez Ortiz, 23 de agosto de 1933). Así mismo, participó y se dio a conocer en el semanario independiente El Adalid (ABC, 31 de julio de 1930), una publicación liberal de la Restauración en Huelva, fundada en 1884 por José Fernández de los Reyes (Díaz Domínguez, 2008). Es precisamente en esta ciudad donde Sánchez Ortiz conoce a José García Cabañas, director del onubense diario La Provincia, a quien califica como su primer maestro (La Provincia, 30 de agosto de 1896).

Pero sobre todo, su labor periodística más importante fue asumir la dirección del diario La Vanguardia, en Barcelona, tras haber sido recomendado a Carlos Godó Pié, fundador de dicha publicación, por Práxedes Mateo Sagasta, presidente del Consejo de Ministros de España, toda vez que las relaciones entre político y empresario eran estrechas, pues La Vanguardia, diario de la familia Godó desde su fundación el 1 de febrero de 1881, fue concebido como 'diario político de avisos y noticias', en sus inicios vinculado en Barcelona a un grupo del Partido Liberal, del que Sagasta era su fundador y primer líder. Así, en su primitiva cabecera figuraba el siguiente título: "Órgano del Partido Constitucional de la provincia".

Su nacimiento se produce en los años inmediatos a la Ley de Policía de Imprenta de 26 de julio de 1883, una normativa favorable a la libertad de expresión reconocida en la Constitución de 1876 y que, entre otras mejoras, suprime la jurisdicción especial para los delitos de imprenta, sometidos a partir de ahora al Código Penal. La nueva legislación, que permanecerá vigente -con algunos intervalos sin

De los nueve hijos de este matrimonio, fallecidos algunos a corta edad, junto a Modesto será su hermano Gerardo, nacido en 1871, quien también se dedique al Periodismo, siendo uno de los fundadores de la Asociación de la Prensa de Madrid. Como se cita en esta investigación, ambos iniciarán una saga de periodistas y escritores en España que llega hasta el siglo XXI, al momento presente. Entre otros, destacan las figuras de Modesto Sánchez de los Santos, Modesto Sánchez de las Casas, Modesto Sánchez Monreal, Fernando Sánchez Monreal y Fernando Sánchez Dragó. Este último autor, sobrino nieto de Modesto Sánchez Ortiz, aporta más información sobre esta familia en algunas de sus obras. Vid. Sánchez Dragó, F. (1986). Las fuentes del Nilo. Barcelona: Planeta y Sánchez Dragó, F. (2006). Muertes paralelas. Barcelona: Planeta. 
aplicación- hasta 1936, posibilita un notable crecimiento del número de periódicos en el país durante el último cuarto del siglo XIX. Así, de los 544 diarios existentes en 1879 , se pasa a 810 cabeceras en 1882 y a 1.128 periódicos en 1887 (Fuentes y Fernández Sebastián, 1998). La Vanguardia también aparece en unos años en los que se experimentan notables cambios en el mundo de la prensa: aumenta el número de lectores, se introducen en las redacciones importantes adelantos tecnológicos, la presencia de la publicidad es cada vez más destacada y comienza a hablarse de prensa de masas. Como señala Castro Sanz (2003: 3) en el anexo 3 de su Tesis Doctoral, "el diario barcelonés surgió en un tiempo favorable desde el punto de vista de la tecnología para la prensa, pero encontró también un campo abonado de experiencias diversas que pudieron ayudarle en la elección de un determinado modelo de referencia".

Designado director a finales de 1887, Sánchez Ortiz inicia su etapa al frente de La Vanguardia en 1888, el año en el que se celebró la Exposición Universal de Barcelona. Con su llegada, el diario deja de ser una publicación del Partido Liberal, y a partir de ese momento se convierte en un periódico de empresa e imparcial a los intereses de los partidos políticos. Además, presenta un nuevo formato $-440 \mathrm{x}$ 290 milímetros-, con una edición matutina y vespertina vigente hasta comienzos de 1890 , cuando se refunden las dos ediciones en una sola, matutina, de ocho páginas (La Vanguardia, 21 de febrero de 1890). Así, puede decirse que el gran cambio del diario catalán aparece justo en ese momento, convirtiéndose en "modelo de diario independiente, plural y moderno" (Grupo Godó, 2007: 28).

En efecto, el periodo de Modesto Sánchez Ortiz al frente de La Vanguardia, entre los años 1888 y 1901, es aplaudido por autores como Voltes Bou (1979) y Casasús Guri (1989), al modernizarlo y convertirlo en el gran diario catalán del siglo XX, a la vez que en uno de los más prestigiosos de Europa. Para ello, el principal modelo de referencia que tuvo fue The Times. Ya en el primer número de La Vanguardia bajo su plena dirección, el 1 de enero de 1888, se hace mención, a modo de una declaración de principios, al ilusionante proyecto que comenzaba a nacer y a la idea de lo que debía ser un diario que reflejara perfectamente la vida de Barcelona, Cataluña y España. Para ello se pusieron en marcha una serie de reformas:

Hemos reorganizado nuestra redacción; hemos formado importante colaboración de escritores conocidos y reputados que enviarán á [sic] nuestro periódico trabajos originales é [sic] inéditos; hemos montado servicios especiales para LA VANGUARDIA, que tendrá al corriente á [sic] sus lectores por medio de telegramas y de cartas de los sucesos más importantes y de las corrientes políticas en Madrid y en las principales capitales de Europa, y hemos establecido, por último, otros servicios de redacción, financiera, comercial, literaria y política para dar al periódico la variedad que el lector tiene derecho á [sic] exigir (La Vanguardia, 1 de enero de 1888: 1). 


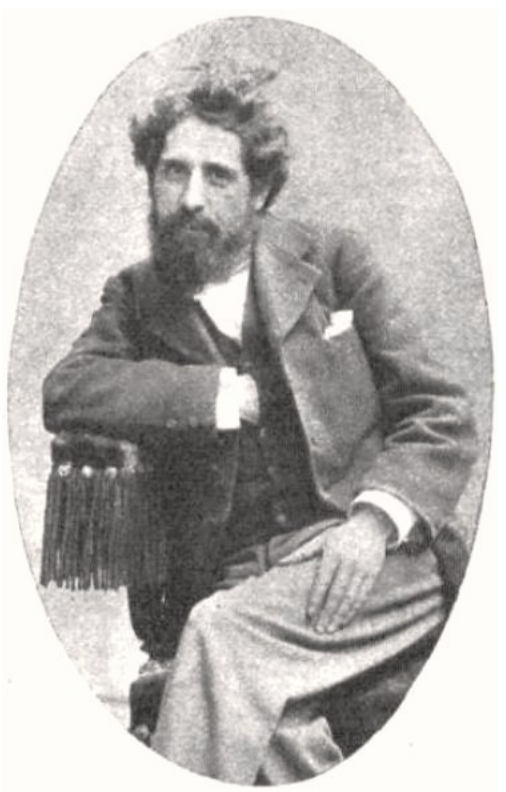

Imagen 1. Retrato de Modesto Sánchez Ortiz.

Fuente: Mundo Gráfico, diciembre de 1932 (especial Cataluña), p. 77.

En 1890 se introducen otros nuevos cambios desde el punto de vista formal, como la inclusión del sumario en la portada y la primera esquela en esta primera página, así como diversos mecanismos para captar nuevos suscriptores y fidelizar a los existentes, sin olvidar la incorporación de nuevas tecnologías y maquinarias a medida que pasaban los años, gracias a la modernización llevada a cabo desde 1897 por Ramón Godó Lallana, nuevo gerente del diario tras la muerte de su padre, Carlos Godó Pié (Nogué y Barrera, 2006).

Durante algo más de una década, Sánchez Ortiz, bajo su rol de director de $L a$ Vanguardia, se integra en la sociedad catalana y en el mundo social y cultural de la cosmopolita ciudad de Barcelona, en los primeros años del modernismo catalán. Así, perteneció o fue miembro de las juntas directivas de organismos como el Ateneo Barcelonés, la Asociación de Amigos de los Pobres o la Asociación de la Prensa de Barcelona. En todas estas entidades conocerá a un nutrido grupo de personas que participarán activamente en el diario. Así lo señala Voltes Bou (1979: 570):

Moviéndose a sus anchas en tertulias y peñas, el director fue captando para el periódico lo más inquieto y significado de la Barcelona intelectual, poniendo buen cuidado -digno del fundador de una orden religiosa- en esquivar, por lo general a figuras senatoriales y consagradas, cuyos nombres podían traer consigo inconvenientes asociaciones de ideas, y preferir a jóvenes promesas, con todo el riesgo que reportaba apostar sobre su futuro.

Del mismo parecer es Manzano (1997: 125): “Sánchez Ortiz tendrá la finísima intuición de conectar con los sectores de la 'otra Barcelona' que emergía del fenómeno 'modernista', agotada ya la vena caudal del 'ochocentismo romántico"'. En efecto, junto a la renovación editorial y de diseño de La Vanguardia, el periodista onubense contará con un variado número de firmas de jóvenes artistas e intelectuales catalanes como Narcis Oller, Santiago Rusiñol, Ramón Casas, Felipe Pedrell, Federico Rahola 
y Trèmols, etc., así como consagrados escritores de la talla de Benito Pérez Galdós, Concha Espina, Azorín o Ramiro de Maeztu, entre muchos otros (Ibáñez Escofet, 1 de febrero de 1981).

Para tener una perspectiva más amplia del apogeo periodístico-cultural de La Vanguardia, Manzano (1997: 125) hace una detallada descripción de algunas de las firmas y sus responsabilidades en el diario barcelonés durante aquellos años, donde aparecen algunos de los anteriores personajes:

A partir de la llegada del periodista onubense a "La Vanguardia" aparecerán páginas firmadas por el doctor Robert; D. José Zulueta; Pompeyo Gener; Narcís Oller. La crítica literaria la pilotará Josep Yxart; Sánchez Ortiz convoca para la critica [sic] de arte a Raimon Caselles. Vireñas Caseñas se encarga de la crítica musical en la que también colaborará el egregio musicólogo D. Felipe Pedrell (que por cierto dedicó un estudio al "cante jondo"). Organiza una red de corresponsales en el extranjero; Miquel Utrillo envía crónicas desde París; Frederic Rahola desde Roma. Coroleu inserta en "La Vanguardia" de la época sus célebres "Memorias de un menestral". Rusiñol, ("Santiaguito", para Sánchez Ortiz) remite noticias de Montmartre redactándolas en su piso de bohemio próximo al "Moulin de La Galette"; sus textos los ilustrará, nada menos que Ramón Casas. La sociedad barcelonesa se solaza leyendo en "La Vanguardia" los artículos de "Juan Buscón".

En estos años finales del siglo XIX, por otro lado, se producirá uno de los episodios más trágicos para España: la pérdida de las últimas colonias de ultramar en América y Asia. La guerra de Cuba culminó el 10 de diciembre de 1898 con la firma del Tratado de París entre España y Estados Unidos. Por el mismo, España perdió Cuba, Filipinas, Puerto Rico y la isla de Guam, que pasaron a manos de Estados Unidos. Es el desastre del 98. Resulta interesante conocer cómo fue su proyección informativa en La Vanguardia, pues coincide con la etapa de Sánchez Ortiz al frente del diario catalán. Los textos que aluden a estos hechos son numerosos y, junto al director onubense, también escribirán sobre este tema de actualidad nacional los periodistas Roca y Roca y Juan Buscón (seudónimo de Ezequiel Boixet), entre otros. Quizá la mejor participación de Sánchez Ortiz sobre este episodio es el artículo "La política en 1898", en el suplemento editado por $L a$ Vanguardia el 1 de enero de 1899. Estos fragmentos de sus párrafos iniciales son esclarecedores:

El epígrafe más propio de todo bosquejo de la política del año sería el año trágico. La comedia de los partidos, convertida en drama por las guerras coloniales, ha terminado en tragedia. Tan á [sic] lo vivo se ha representado, que del teatro nacional no ha quedado nada indemne: los comediantes destrozados, el público mal herido [sic], el escenario mismo amenazando inminente ruina. Las páginas luminosas de la historia de España han quedado manchadas con tacas imborrables. El descubrimiento y civilización de América, la conquista y civilización de Filipinas, cuatro siglos de dominación en los mares de Oriente y Occidente, la leyenda de nuestras grandezas han quedado sepultados en el abismo que representa para nuestra nación este año trágico. La poesía de las grandes tristezas le dedicará acentos desgarrados; el historiador anotará sus días luctuosos; el sociólogo buscará en las entrañas de nuestra constitución histórica, política y social, clasificándolas y relacionándolas, las causas que han producido el desastre de 1898; el periodista no puede más que ponerle el epitafio. 
El Protocolo y el Tratado de Paz de París, como síntesis de nuestra decadencia, como ley de nuestra desmembración colonial, quizás como punto de partida de nuevos peligros para la nacionalidad española, no es, ¡ojalá fuera solamente eso! el desastre de un Gobierno, ni el de un partido, ni el de un régimen en el sentido limitado que la política militante da á [sic] la palabra. Es el desastre de toda la España directiva. [...] Sin que toda la España directiva, sin distinción de partidos ni de clases, haga virilmente un examen de conciencia y se aplique el cauterio en las regiones llagadas de su alma ó [sic] de su cuerpo, no se hará el verdadero proceso del desastre nacional ni habrá justificada esperanza de renacimiento (Sánchez Ortiz, 1 de enero de 1899: 4).

1898 marcará un antes y un después en el Periodismo español. A partir de este momento, por algún tiempo la prensa hispana tomará el camino de la resignación, junto con una actitud crítica que se impondrá sobre la indiferencia del desánimo por lo sucedido (Voltes Bou, 1983).

Habiendo alcanzado un notable éxito y con una prometedora carrera periodística por delante, por motivos de salud Modesto Sánchez decide abandonar la dirección de La Vanguardia a finales de 1901, tras casi catorce años bajo su dirección, en los que había dejado un diario ya completamente renovado. En la información de su renuncia se le llega a calificar como un hombre de "inteligencia superior, cumplido caballero y maestro en periodismo" (La Vanguardia, 17 de octubre de 1901: 2). Y es que su nombre siempre estará unido a este diario catalán.

En los siguientes años se dedica especialmente a la Política, pero no deja de escribir, alternando su nueva actividad laboral con la de periodista y articulista. Así, por ejemplo, desde febrero de 1905 (La Época, 21 de febrero de 1905) hasta el 4 de julio de ese año será director del diario El Correo, donde había sido redactor durante ocho años antes de capitanear La Vanguardia. Renunció a este cargo al ser nombrado gobernador civil de Castellón (Diario oficial de avisos de Madrid, 5 de julio de 1905). Por esa fecha se colegia en la Asociación de la Prensa de Madrid, fundada el 31 de mayo de 1895 por su hermano Gerardo, entre otros periodistas (Carmona y Caballero, 2010b).

Aunque ocupado por sus distintos trabajos en el Gobierno nacional y en el Ministerio de Hacienda, el periodista onubense realiza algunas colaboraciones periodísticas en la España del final y crisis de la Restauración, dictadura de Primo de Rivera y Segunda República, en una prensa -independiente o partidista- cada vez más politizada que, en ocasiones, fue censurada o suspendida por los diferentes gobiernos. Escribirá con su nombre, aunque a veces también firmará como 'Juan de Onuba', 'Simón de la Redondela' o 'Alja-Raque', unos pseudónimos relacionados claramente con sus orígenes onubenses.

En los últimos años de vida pública en los diarios El Heraldo de Madrid y El Imparcial las que serán sus memorias, bajo el título 'Memorias de un ochentón' o 'Testimonios de un ochentón', en 1932 y 1933, donde desgrana anécdotas y hechos relevantes de su época como periodista y político, por ejemplo de sus inicios en el mundo del Periodismo y su vida en Madrid y Barcelona. A punto de cumplir los 80 años, Modesto Sánchez Ortiz fallece en Madrid el 11 de enero de 1937. Su muerte, en plena Guerra Civil, pasó casi desapercibida en los medios de comunicación de España, que dedicaron un reducido espacio informativo a su pérdida, como en el caso de La Vanguardia (12 de enero de 1937), con unas pocas líneas 
que no hacían honor a una figura tan imprescindible para este diario tan solo unas décadas antes.

En cuanto a su vida privada, Modesto Sánchez Ortiz se casó en primeras nupcias con Isabel de los Santos y Liberto, fallecida a finales de 1901, desposándose posteriormente con Mariana Siet Ascoz. De esta última unión nacería su hija Modesta (Carmona y Caballero, 2010a). Fruto de su primer matrimonio vino al mundo su hijo Modesto Sánchez de los Santos, también periodista y autor de varios libros, al igual que el hijo de éste, Modesto Sánchez de las Casas (Carmona y Caballero, 2010b). Por otro lado, conocemos que la vivienda familiar en la capital española, denominada 'hotel' u 'hotelito', se encontraba en la Colonia de la Prensa de Madrid ( La Voz, 12 de marzo de 1929).

A pesar de vivir en Madrid, Barcelona y varias ciudades más, Sánchez Ortiz nunca olvidó sus raíces onubenses. Durante muchos años viajó el periodista hasta Aljaraque, generalmente en verano, donde sufragó algunas mejoras en el municipio. Por ejemplo, ayudó a constituir la sociedad Amigos del Alfabeto, con dedicación a la enseñanza popular (La Correspondencia de España, 9 de octubre de 1902). Recibió en vida numerosos homenajes, entre otros los tributados por sus compañeros periodistas de Madrid, Barcelona y Huelva; uno de los últimos fue el que le dedicó la Asociación de la Prensa de Huelva en agosto de 1927 (La Provincia, 20 de agosto de 1927). Años más tarde, en honor a su trayectoria profesional y a su contribución para el desarrollo local, el Ayuntamiento de Aljaraque le dedicó una calle donde estuvo su casa natal, con una lápida que se descubrió el 9 de agosto de 1931 ( $\mathrm{La} \mathrm{Voz}$, 11 de agosto de 1931). En la actualidad, a pesar de las vicisitudes históricas y de los numerosos vaivenes políticos, esta calle aljaraqueña continúa rotulada con su ilustre nombre.

\section{Actividad política y red de contactos}

Para apreciar la evolución vital de Modesto Sánchez Ortiz, junto a su faceta comunicativa es necesario de dar a conocer su labor vinculada a la Política. Así, como punto de partida conocemos que el periodista onubense estaba afiliado al Partido Liberal desde una edad temprana, probablemente poco antes de 1882 (El Globo, 5 de enero de 1906), y que era amigo personal de Sagasta. Precisamente, su vinculación política fue la que le abrió las puertas de algunas redacciones en esos años finales del siglo XIX, como hemos visto, por ejemplo, en el caso de La Vanguardia. Y gracias a su membresía liberalista, además, pudo conocer a influyentes personas que le ayudarían a ascender en el mundo político, con lo que logró ocupar importantes cargos en la Administración.

La investigación realizada en la prensa histórica de la hemeroteca digital de la Biblioteca Nacional de España nos revela algunos datos interesantes sobre Sánchez Ortiz, muchos de ellos desconocidos. Tras su marcha de La Vanguardia, a finales de 1901, comienza a dedicarse de manera casi íntegra a la Política aunque, como hemos visto, no acaba con su labor periodística. Tan sólo unos meses antes, su adhesión al Partido Liberal y la insistencia de sus compañeros políticos le hicieron presentarse a las elecciones generales españolas de mayo de 1901, en las que resultó elegido diputado a Cortes por el distrito de Mataró. Esta etapa culminó el 27 de marzo de 1903 (Congreso de los Diputados, s.f.). 
En los años siguientes fue nombrado gobernador civil de las provincias de Castellón, Gerona, Almería, Lugo, Oviedo y Burgos. Nuestra indagación señala, por otra parte, que también ocupó distintos cargos en el Ministerio de Hacienda, como los de oficial mayor de la secretaría del Ministerio, con la categoría de jefe de administración civil de primera clase; interventor de Hacienda en Murcia y Guadalajara, además de otras ocupaciones, como la de secretario de la Federación Nacional de Fabricantes de Azúcar.

En conclusión, la actividad política de Modesto Sánchez Ortiz hizo que también fuera bien conocido en esta faceta, al ocupar distintos cargos gubernamentales de considerable responsabilidad en varias provincias de España. Ciertamente, además de poseer un gran talento y unos méritos propios cosechados en el mundo del Periodismo y de la Política, su pertenencia al Partido Liberal y la configuración de una nutrida red de contactos ayudó a que estuviera en el candelero durante muchos años.

\section{Teórico del Periodismo español}

A lo largo de sus casi ochenta años de vida, Modesto Sánchez Ortiz escribe numerosos artículos y libros. Entre su producción literaria se encuentran varias obras de vertiente política: Las primeras Cámaras de la Regencia: datos electorales, estadísticos y biográficos (1886), escrita conjuntamente con Fermín Berástegui; Las Cortes Españolas. Las de 1907 (1908), de su hijo Modesto Sánchez de los Santos y con la colaboración del periodista onubense, que firma bajo el pseudónimo 'Juan de Onuba', y Las Cortes Españolas. Las de 1910 y Las Cortes Españolas. Las de 1914, también de Modesto Sánchez de los Santos, dos libros en los que nuestro autor objeto de estudio firma con el nombre de 'Simón de la Redondela', en honor a su padre y a la localidad onubense de donde era originaria su familia paterna. Pero el principal libro que escribió -y más importante para nuestro artículo- fue El Periodismo (1903). Es por ello que, al considerarla como un manual para la profesión periodística de aquellos años y los siguientes, la analizamos a continuación.

Los estudios de Altabella Hernández (1983), Álvarez et al. (1989), Casasús Guri (1990) y Aubert (2010), entre otros, han sacado a la luz de la comunidad científica las obras de autores de finales del siglo XIX y principios del XX que escribieron sobre cuestiones periodísticas. De comienzos de la pasada centuria y contemporáneos a la obra de Sánchez Ortiz se encuentran los trabajos de Jerez Perchet (1901), Cabazán (1901) y Baró y Sureda (1902), así como las aportaciones sobre la profesión periodística de Mainar (1906), López Peláez (1907), Minguijón (1908), de Aragón (1909), Álvarez (1912) o Morató i Grau (1918), entre otros.

Como podemos apreciar en la anterior enumeración, según el año de aparición la obra de Sánchez Ortiz se encuentra entre las primeras que se publicaron sobre la temática referida en el siglo XX. Y, además, se constituye como una útil aportación para la profesión y la Academia, según el número de autores que citan El Periodis$m o$. Entre los investigadores que han analizado con más interés el libro del periodista onubense, o han reparado con mayor afán científico en él, se encuentran el mencionado profesor Casasús, quien en 1990 realiza un estudio introductorio en una edición facsímil sobre El Periodismo, así como García Galindo (2005) y, más recientemente, Rodríguez Rodríguez (2016). Todos ellos hacen referencia en sus trabajos a diversos aspectos vitales en la obra de Sánchez Ortiz, como el contexto de la profesión perio- 
dística en el cambio de siglo y, especialmente, sobre el papel y la evidente necesidad de formación de los periodistas.

En nuestro caso, a pesar del citado interés académico hacia El Periodismo, y sin intención de realizar un estudio pormenorizado sobre esta obra, sí creemos conveniente detenernos a aportar y comentar algunos de los aspectos que más nos han llamado la atención sobre este manual periodístico de referencia, divididos en varios subepígrafes.

\subsection{El Periodismo como sacerdocio y magisterio}

Después del desastre del 98, Sánchez Ortiz tenía una gran preocupación por el papel que la prensa del entrante siglo XX debía cumplir con objetivo de formar a una sociedad en buena medida analfabeta y con una clase política corrompida. Así, como se indica en el anterior título, sostiene que el Periodismo es para él sacerdocio y magisterio. En primer lugar, para este autor el Periodismo es sacerdocio "en cuanto es disciplina, perfeccionamiento, preparación del espíritu del hombre para la vida moral, en cuanto es propagación de la Verdad y del Bien" (Sánchez Ortiz, 1903: 9). Y magisterio porque debe "aleccionar al hombre en colectividad, en todas las manifestaciones de la inteligencia y en todas las actividades del espíritu, exponer y divulgar la doctrina en ciencias, en artes y en oficios" (Ibid.: 9).

Para Sánchez Ortiz, que consideraba a la prensa como "carne de mi carne" (Ibíd.: 5) y "madre" (Ibid.: 6), en términos eclesiásticos le concibe al periodista un importante papel en la sociedad como apóstol, destacando su necesario sentido ético. Crítico y contrario a la presencia del criterio industrial (con objeto de negocio) en el Periodismo, frente al criterio profesional (con conciencia y orientación a la verdad), el tratadista defiende al comienzo de su libro la importancia de que el trabajo del periodista sea remunerador a su esfuerzo, aunque sin ánimo de lucro. Así se refiere al carácter de la disciplina abordada: "El periodismo, como las demás profesiones semejantes, es, por naturaleza, altruista, y cuanto se separe de esa inspiración en la finalidad ó [sic] en la conducta, fuera del grado remunerador con la significación expuesta, lo desnaturaliza y adultera" (Ibid.: 14).

\subsection{Estado del Periodismo español}

El Periodismo se constituye como una completa radiografía de la situación periodística del país a comienzos del siglo XX. Sánchez Ortiz se hace eco en su obra del estado de esta disciplina, una profesión que según él necesitaba de algo más para ser ideal. Y no, precisamente, de convertirse en una carrera universitaria, bajo la regulación del Estado. Sin embargo, en su trabajo fue más entusiasta con la idea de una correcta formación para los que se inician en las tareas informativas, ya que sostiene que su objetivo principal es "señalar la necesidad de dar al periodista una preparación adecuada á [sic] sus funciones, como sucede ya en Estados de mayor cultura" (Ibid.: 18).

Sobre las múltiples cualidades del periodista español, Sánchez Ortiz destaca que "es sencillamente admirable por la calidad de su materia prima intelectual, por su profundo y flexible talento, por su imaginación exuberante y viva" (Ibíd.: 31). Además, añade que "en los periódicos españoles puede encontrarse todos los días el espíritu profundo y abstracto del alemán, la fuerza de observación y análisis del inglés, 
la imaginación ardiente y el sentimiento apasionado del italiano, el chispeante ingenio del francés..." (Ibíd.: 32). Sin embargo, continúa Sánchez Ortiz más adelante, esta profesión no merece en España la misma valoración salarial que tiene en otras naciones:

El periodismo no es oficio pagado en España ni en comparación con los periodistas extranjeros ni comparándolo con otra profesión cualquiera, como no sean las nobilísimas profesiones que el Estado -se entiende, el Estado español- requiere para sus funciones fundamentales: las armas, la toga, la enseñanza, etc. (Ibid.: 32-33).

\subsection{Periodismo de empresa frente al periodismo de partido}

En relación con el apartado anterior, en los años precedentes a la publicación de $E l$ Periodismo era frecuente que los partidos políticos editasen periódicos y diarios, o que al menos influyeran en los mismos. En este sentido, tras analizar varios modelos de periódico, Sánchez Ortiz se detiene a comparar el periodismo de partido con respecto al periodismo de empresa. En estos dos tipos, el autor ve algunos aspectos positivos, si bien son más frecuentes los negativos, por ejemplo la dependencia de la prensa de agrupaciones políticas y de banqueros o familias, con sus vicios e intereses personales.

Para Sánchez Ortiz, lo más idóneo en el Periodismo es la independencia del periodista, que debe actuar de forma profesional, como bien explica en estas líneas:

La garantía auténtica, la mayor, por no decir la única, la más eficaz de la justicia en el periodismo, está y estará siempre, hasta cuando periodistas y empresas sean completamente independientes del negocio y entre sí, hasta cuando cambie radicalmente la constitución del oficio, esa garantía está y estará siempre, pero mucho más ahora, en la energía moral del periodista, en el dominio de sus pasiones, en el equilibrio de su inteligencia y en la extensión de su cultura para apreciar la complejidad de la vida, manifiesta en cada caso de los que examina y juzga; está en los refinamientos del sentido ético del periodista, y en su patriotismo y en su amor al prójimo, verdaderos y absolutos factores de la bondad de nuestros trabajos (Ibid.: 28-29).

Finalmente, después de alabar el periódico de partido en España, Sánchez Ortiz se centra en el periódico de empresa y sus logros pasados y presentes, ya que "como en los países más florecientes, es tan hermoso como la vida misma, porque es su espejo, y su fotografía, y su eco, porque es ella repetida, embellecida á [sic] veces..." (Ibíd.: 30).

\subsection{Algunos pecados periodísticos}

Por otra parte, Sánchez Ortiz aprovecha esta publicación para confesarse, en primer lugar sobre los incorrectos hábitos de los periodistas $\mathrm{y}$, seguidamente, para denominarse pecador. Así, en estas líneas de El Periodismo comenta todos los pecados periodísticos cometidos en el pasado, tanto los personales como de los periódicos de empresa y de partido, tales como mala praxis profesional, engaño al lector, la tiranía 
del poder que ejercen estos medios, la impunidad del daño periodístico, la existencia de testaferros, la inmunidad parlamentaria, etc. Surgen en estas líneas términos y conceptos como responsabilidad, imparcialidad y verdad que resultan interesantes en su pensamiento deontológico del Periodismo.

La figura del testaferro es condenada por Sánchez Ortiz, que pide que desaparezca, a pesar de ser pocos los casos dados en el Periodismo español. Para él, el único responsable de todos sus actos, como decimos, es el propio periodista.

Finalmente, reflexiona sobre el peligro de la palabra del periodista, que en ocasiones no es del todo bien intencionada:

Conocemos los periodistas el poder de la gota de agua en la piedra y el poder de nuestra palabra en el espíritu del lector, de nuestro lector, que, por ser meridional, es á [sic] la vez perezoso y exaltado en el discurso propio, y, por tanto, fácilmente asequible y manejable por el discurso ajeno. Sabemos que influímos [sic] tanto en los actos de los gobernantes como de los gobernados, y, sin embargo, rechazamos por sistema toda solidaridad con unos y con otros, en cuanto los actos que nosotros preparamos y determinamos son causas inmediatas de un daño evidente, en cuanto tocan á [sic] responsabilidad. No hay derrumbamiento que nos coja, ni inundación que nos alcance... Y me alegraría de ello por nosotros si tras de esa indemnidad nuestra no hubiera un grave daño para todo lo demás, para la justicia, para el país y para nosotros mismos, porque no habiendo reconocimiento de la falta, no hay enmienda posible (Ibíd:: 87).

\subsection{Asociacionismo periodístico}

Por último, nos detenemos en un punto interesante, como es el llamamiento de Sánchez Ortiz hacia un activismo o, mejor expresado, asociacionismo periodístico. El periodista onubense intenta, a través de sus últimas páginas, movilizar a los diarios y periodistas españoles para reconstituir entre todos el país, que no estaba afectado solo por el reciente desastre del 98 , sino por la mala praxis y desgana de su clase política.

Sánchez Ortiz conocía con gran acierto que la prensa española era muy influyente, a la que consideraba como un "poder mucho más intenso y extenso que el del Gobierno, como poder el más rápido y seguro para modificar el estado político, intelectual y moral de la nación" (Ibid.: 89). Según él, en un primer momento la acción regeneradora de la nación correspondería a los partidos, Gobiernos y Cortes, pero desecha finalmente este camino, pues "han sido fuerzas activas para la degeneración" (Ibid.: 92). En su lugar, aboga por la prensa para que inicie la acción de la obra regeneradora, mediante la asociación. Así lo afirma:

Y á [sic] la asociación formada por la Prensa directamente alguna vez, y otras veces formada por su iniciativa y bajo su amparo por otros elementos sociales, confío la obra redentora, la obra magna de reaccionar en nuestra España contra tantos fermentos de descomposición y muerte (Ibid.: 93).

A través de estas acciones, el periodista propone modificar la conciencia pública y eliminar el caciquismo, un gran mal de la política cuanto más local es. Por ello, expresa en estas líneas la promoción de asociaciones por parte de la prensa para fomentar la enseñanza primaria de los españoles para que dejen de ser ignorantes, analfabetos y, por supuesto, para la gran reconstitución nacional. Como sentencia 
Sánchez Ortiz (Ibíd:: 96), “querer es poder. Y la prensa española, singularmente los grandes periódicos, pueden aumentar la lista de los extraordinarios servicios á [sic] su patria, tomando á [sic] su cargo la grata tarea de rescatarla del vilipendio y de la muerte".

\section{Conclusiones}

Conocido por sus facetas política e informativa a partes iguales, Modesto Sánchez Ortiz fue un intelectual onubense que desarrolló su trabajo lejos de su tierra. Su actividad laboral en las principales ciudades de España le hizo rodearse de un gran número de personas, muchas de ellas al amparo del Partido Liberal, consiguiendo tal vez con un poco de ayuda inicial y por méritos propios ser una de las figuras más reconocidas en el Periodismo español de finales del siglo XIX y principios de la siguiente centuria.

A pesar de ello, como hemos visto, son escasas las publicaciones que aportan datos interesantes sobre su biografía, y en la mayoría de las ocasiones solo destacan la realización del libro El Periodismo y la dirección de La Vanguardia. Sin embargo, con nuestra investigación hemos descubierto nuevos detalles interesantes sobre su perfil periodístico, como la existencia de unas memorias publicadas en El Heraldo de Madrid y El Imparcial, además de la firma de artículos y libros, en ocasiones, bajo los pseudónimos 'Juan de Onuba', 'Simón de la Redondela' o 'Alja-Raque', en alusión a su procedencia onubense y a la de su familia. Igualmente, resaltamos que Sánchez Ortiz trabajó y colaboró en varios periódicos y que asumió la dirección de El Correo y La Vanguardia, siendo efectivamente muy reconocido por su ejemplar labor al frente de este último medio de comunicación. Sin duda, fue uno de los principales promotores del Periodismo catalán, con su actividad dinámica en la Asociación de la Prensa de Barcelona y por los numerosos cambios introducidos en La Vanguardia, que se convirtió en un diario de referencia para el nacimiento de una cultura modernista que sería el pilar fundamental para entender actualmente la idiosincrasia de la ciudad condal.

Por otro lado, con la realización de su obra El Periodismo, el periodista onubense plasmó su visión sobre la profesión periodística y logró establecer una comparación entre la situación del sector en nuestro país y en el extranjero. En una época donde no existía carrera universitaria para esta disciplina informativa, Sánchez Ortiz propone una formación para mejorar la calidad del Periodismo y, algo más importante, el asociacionismo de la prensa y de los periodistas de España para intentar cambiar la sociedad y el rumbo del país, en la etapa posterior al desastre del 98 y enmarcado dentro del movimiento intelectual del regeneracionismo.

En conclusión, en estas líneas rescatamos a una figura crucial del Periodismo español y aportamos inéditos datos sobre su transcurrir vital, con la pretensión final de reconocer la importancia de un periodista injustamente poco recordado en la actualidad. Útil y necesario sería, en este sentido, abordar y poner en relación en próximas investigaciones a Modesto Sánchez Ortiz con su hermano Gerardo y toda su descendencia de periodistas, los Sánchez, que con unos orígenes onubenses se expandieron por toda España. 


\section{Referencias}

$A B C$, "Iniciativa plausible", 31-07-1930, p. 22.

Altabella Hernández, J. (1983). Fuentes crítico-bibliográficas para la historia de la prensa provincial española. Tesis doctoral. Departamento de Historia, Universidad Complutense de Madrid. Madrid: Editorial de la Universidad Complutense.

Álvarez, B. (1912). El libro del periodista. Madrid: Imprenta de Juan Pueyo.

Álvarez, J. T. (et al.) (1989). Historia de los medios de comunicación en España. Periodismo, imagen y publicidad (1900-1990). Barcelona: Ariel.

Aragón, J. DE (1909). El periodismo moderno. Madrid: s. e.

Aubert, P. (2010). “La historia que pasa': Rafael Mainar Lahuerta y El arte del periodista”. En Ludec, N. Y Sarría Buil, A. (coords.) (2010). La morfología de la prensa y del impreso: la función expresiva de las formas: Homenaje a Jean-Michel Desvois. París: Pilar, pp. 277-296.

Baró y Sureda, T. (1902). El periodismo. Barcelona: s.e.

Cabazán, A. (1901). Cómo debe ser la prensa moderna. Jaén: s.e.

Carmona, A. y Caballero, P. (2010a). "Simón Sánchez Díaz, bisabuelo de Fernando Sánchez Dragó, nació en La Redondela (I)”, La Higuerita, 01-12-2010, p. 14.

- (2010b). "Simón Sánchez Díaz, bisabuelo de Fernando Sánchez Dragó, nació en La Redondela (II)", La Higuerita, 15-12-2010, p. 15.

Casasús Guri, J. M. (1989). "Dades inèdites del debat teòric sobre periodisme a la Catalunya del tombant de segle”. En: Anàlisi: quaderns de comunicació i cultura, n 12, Barcelona: Universidad Autónoma de Barcelona, pp. 119-126.

- (1990). Estudio introductorio al libro de Modesto Sánchez Ortiz, El periodismo, Madrid, M. Romero Impresor, 1903, edición facsímil. Barcelona: Fundación Conde de Barcelona.

Castro Sanz, C. (2003). La reconversión tecnológica y empresarial en un periódico consolidado: el caso de "La Vanguardia". Tesis doctoral. Departamento de Comunicación Audiovisual y Publicidad, Universidad Autónoma de Barcelona. Consultado el 22 de marzo de 2017 en: https://ddd.uab.cat/record/36867

Congreso de los Diputados (s.f). Ficha de Sánchez Ortiz, Modesto. Consultado el 12 de marzo de 2017 en: http://www.congreso.es/portal/page/portal/Congreso/Congreso/SDocum/ArchCon/SDHistoDipu/SDIndHistDip?_piref73_1340024_73_1340023_1340023. next_page $=/ \mathrm{wc} /$ servidorCGI\&CMD $=$ VERLST \&BASE $=$ DIPH\&FMT $=$ DIPHXD $1 \mathrm{~S}$. fmt \&DOCS $=1-1 \&$ DOCORDER $=$ FIFO \&OPDEF $=$ Y \&NUM $1=\& D E S 1=\&-$ QUERY=\%28105490\%29.NDIP.

Diario oficial de avisos de Madrid, "Noticias", 05-07-1905, p. 3.

Díaz Domínguez, Mª P. (2008). "La prensa política como fuente histórica en el estudio de la Restauración en España. El caso de Huelva (1874-1923)". En Heredia Urzáiz, I. y Aldunate León, O. (2008). Actas del I Encuentro de Jóvenes Investigadores en Historia Contemporánea de la Asociación de Historia Contemporánea (Zaragoza, 26, 27 y 28 de septiembre de 2007). Zaragoza: Prensas Universitarias de Zaragoza. Consultado el 16 de abril de 2017 en: http://ifc.dpz.es/recursos/publicaciones/27/15/75.mpazdiaz.pdf

El Globo, "Información política", 05-01-1906, p. 3.

Fuentes, J. F. Y Fernández Sebastián, J. (1998). Historia del periodismo español: prensa, política y opinión pública en la España contemporánea. Madrid: Síntesis.

García Galindo, J. A. (2005). "Estudios de periodismo. Los primeros tratadistas españoles". En Desvois, J-M. (coord.). Prensa, impresos, lectura en el mundo hispánico contemporáneo: homenaje a Jean-François Botrel. Pessac: Pilar, pp. 179-192. 
Grupo Godó (2007). "La Vanguardia. 125 años como el diario de referencia de Catalunya”. En Memoria 2016. S.1: s.e. pp. 28-33.

Ibáñez Escofet, M. (01-02-1981). “'La Vanguardia’ como fenómeno cultural. Una tradición de sensibilidad, inquietud y refinamiento literario”, La Vanguardia, p. 49 y 95.

JEREZ PERCHET, A. (1901). Tratado de periodismo. Granada: Imprenta de El Defensor de Granada.

La Correspondencia de España, "Noticias", 09-10-1902, p. 3.

La Época, "La dirección de 'El Correo"”, 21-02-1905, p. 2.

La Provincia (30-08-1896), "En honor de Sánchez Ortiz”, p. 2.

- (20-08-1927), "En la Asociación de la Prensa. Homenaje a un periodista ilustre”, p. 3.

La Vanguardia (01-01-1888) (edición de la mañana), “A nuestros lectores”, p. 1.

— (21-02-1890), "Las reformas de 'La Vanguardia”,, pp. 1-2.

- (17-10-1901), "Notas locales”, p. 2.

- (12-01-1937), "Periodista fallecido", p. 5.

La Voz (12-03-1929), "Los amigos de lo ajeno", p. 3.

- (11-08-1931), "Homenaje a un periodista", p. 3.

López Peláez, A. (1907). La importancia de la prensa. Barcelona: Gustavo Gili.

Mainar, R. (1906). El arte del periodista. Barcelona: José Gallach.

Manzano, R. (1997). Huelva en los labios. Huelva: Diputación Provincial de Huelva, servicio de publicaciones.

Minguijón, S. (1908). Las luchas del periodismo. Zaragoza: Tip. Salas.

Morató I Grau, J. (1918). Com es fet un diari. Barcelona: Ricard Duran i Alsina.

Nogué, A. y Barrera, C. (2006). La Vanguardia, del franquismo a la democracia. Madrid: Fragua.

Rodríguez Rodríguez, J. M. (2016). "Rasgos de la figura del periodista en los primeros tratados de periodismo en España. Hacia una identidad profesional (1891-1912)". En: Revista de Comunicación, $\mathrm{n}^{\circ}$ 15, Piura: Universidad de Piura. pp. 86-110.

Sánchez De Los Santos, M. y Onuba, J. De (1908). Las Cortes Españolas. Las de 1907. Madrid: Establecimiento tipográfico de Antonio Marzo.

Sánchez De Los Santos, M. y Redondela, S. de la (1910). Las Cortes Españolas. Las de 1910. Madrid: Establecimiento tipográfico de A. Marzo.

- (1914). Las Cortes Españolas. Las de 1914. Madrid: Establecimiento tipográfico de A. Marzo.

Sánchez Dragó, F. (1986). Las fuentes del Nilo. Barcelona: Planeta.

- (2006). Muertes paralelas. Barcelona: Planeta.

Sánchez Ortiz, M. (01-01-1899), "La política en 1898”, La Vanguardia, suplemento, p. 4.

- (1903). El Periodismo. (Prólogo del libro El País, La Política, La Prensa). Madrid: M. Romero.

- (24-01-1933), “"El Imparcial' y 'El Liberal””, El Imparcial, p. 3.

- (23-08-1933), "Efemérides sangrienta”, El Heraldo de Madrid, p. 5.

Sánchez Ortiz, M. y Berástegui, F. (1886). Las primeras Cámaras de la Regencia: datos electorales, estadísticos y biográficos. Madrid: Imprenta de Enrique Rubiños.

Sanmartí Roset, J. M. (2016). "La Vanguardia, el liberalismo conservador y catalanista con la II República”. En: El Argonauta Español, n 13, Aix-en-Provence: Maison Méditerranéenne des Sciences de l'Homme. Consultado el 3 de julio de 2017 en: http://argonauta. revues.org/2490

Voltes Bou, P. (1979). “El onubense Modesto Sánchez Ortiz, director de 'La Vanguardia' de Barcelona”. En: Andalucía Contemporánea (siglos XIX y XX), tomo II. Actas del I Con- 
greso de Historia de Andalucía, diciembre de 1976. Córdoba: Publicaciones del Monte de Piedad y Caja de Ahorros de Córdoba. pp. 569-574.

- (1983). Nuevo análisis de los antecedentes de la guerra de 1898. Cuadernos de economía: Spanish Journal of Economics and Finance, vol. 11, n 11, Madrid: Universidad Autónoma de Madrid. pp. 313-353. 